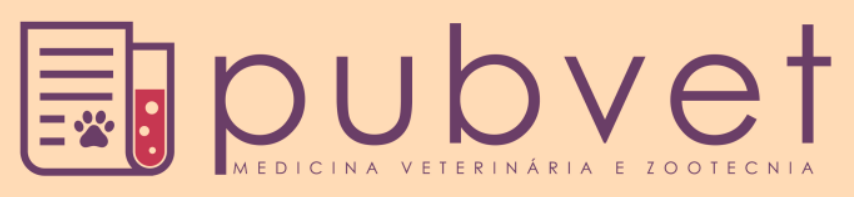

https://doi.org/10.22256/pubvet.v12n6a108.1-4

\title{
Detecção molecular de Babesia canis vogeli em cães da cidade de São Luís - MA, Brasil
}

\author{
Lygia Silva Galeno ${ }^{\bullet} 1^{*}$, Brenda Fernanda Sodré Moreno ${ }^{\bullet 1}$, Andressa Mendes Alves ${ }^{\bullet}$, \\ Walkyria Conceição Fonseca ${ }^{\ominus 1}$, Clarissa Costa Durães ${ }^{\ominus 1}$, Douglas Marinho Abreu ${ }^{\ominus 1}$, \\ Italo Marcelo Reis da Silva ${ }^{\bullet}$, Patrícia Thallyta Rocha Ferreira ${ }^{\bullet}$, Daniel Praseres \\ Chaves 22
}

${ }^{I}$ Discente em Universidade Estadual do Maranhão, Campus Paulo VI. São Luís - MA. Brasil. E-mail: lygiagaleno@outlook.com, brendafernandasm@gmail.com, andressamalves@outlook.com, walkyriaconceicao@hotmail.com, clarissaduraes@hotmail.com, abreu.dmarinho@gmail.com, marcelo_reis20@hotmail.com, patricia_thallyta@hotmail.com

${ }^{2}$ Docente do Departamento de Patologia, Universidade Estadual do Maranhão, Campus Paulo VI. São Luís - MA. Brasil. E-mail: daniel@cernitas.com.br *Autor para correspondência, lygiagaleno@outlook.com

RESUMO. A babesiose é uma enfermidade emergente, de distribuição mundial, causada por protozoários do gênero Babesia, que afeta animais domésticos e animais selvagens, bem como em humanos. O objetivo deste estudo foi determinar a ocorrência de Babesia canis vogeli em cães na cidade de São Luís - MA, Brasil. Foram coletadas amostras de sangue de 65 animais para exame direto, por meio do esfregaço sanguíneo e diagnóstico molecular, por meio do PCRun. Dentre os 65 animais analisados por meio do diagnóstico direto, nenhum foi positivo para Babesia spp. enquanto pela PCRun, constatou-se que $5(7,69 \%)$ estavam infectados por B. canis vogeli, demonstrando a presença dessa espécie em cães provenientes de ambiente urbano na cidade de São Luís. Concluiu-se que a PCR é uma técnica mais sensível e específica para esse diagnóstico, podendo ser utilizada para definir com maior precisão a infecção de cães por B. canis vogeli. Este estudo confirmou a presença de B. C. vogeli em cães na cidade de São Luís - MA.

Palavras chave: $B$. canis vogeli, cães, diagnóstico direto, PCR

\section{Molecular detection of Babesia canis vogeli in dogs in the city of São Luís - MA, Brazil}

\begin{abstract}
Babesiosis is an emerging, worldwide disease caused by protozoa of the genus Babesia, which infects domestic animals and wildlife, as well as humans. The objective of this study was to determine the occurrence of Babesia canis vogeli in dogs in the city of São Luís - MA, Brazil. Blood samples were collected from 65 animals for direct examination, through blood smear and molecular diagnosis, through PCRun. Among the 65 animals analyzed by direct diagnosis, none were positive for Babesia spp. while PCRun showed that 5 (7.69\%) were infected by B. canis vogeli, demonstrating the presence of this species in dogs from an urban environment in the city of São Luís. It was concluded that PCR is a more sensitive and specific for this diagnosis, and can be used to define more precisely the infection of $\operatorname{dogs}$ by B. canis vogeli. This study confirmed the presence of B. C. vogeli in dogs in the city of.
\end{abstract}

Keywords: B. canis vogeli, dogs, direct diagnosis, PCR 


\section{Detección molecular de Babesia canis vogeli en perros en la ciudad de São Luís - MA, Brasil}

RESUMEN. La babesiosis es una enfermedad emergente, de distribución mundial, causada por protozoarios del género Babesia, que infecta animales domésticos y animales salvajes, así como en humanos. El objetivo de este estudio fue determinar la ocurrencia de Babesia canis vogeli en perros en la ciudad de São Luís - MA, Brasil. Se recogieron muestras de sangre de 65 animales para examen directo, por medio del frotis sanguíneo y diagnóstico molecular, por medio del PCRun. Entre los 65 animales analizados por medio del diagnóstico directo, ninguno fue positivo para Babesia spp. y en el caso de la PCRun, se constató que $5(7,69 \%)$ estaban infectados por B. canis vogeli, demostrando la presencia de esta especie en perros provenientes de ambiente urbano en la ciudad de São Luís. Se concluyó que la PCR es una técnica más sensible y específica para ese diagnóstico, pudiendo ser utilizada para definir con mayor precisión la infección de perros por $B$. canis vogeli. Este estudio confirmó la presencia de B. C. vogeli en perros en la ciudad de São Luís - MA.

Palabras clave: $B$. canis vogeli, perros, diagnóstico directo, PCR

\section{Introdução}

A babesiose canina é uma enfermidade de distribuição mundial e com grande importância veterinária, causada por protozoários do gênero Babesia, sendo as espécies B. canis e B. gibsoni que mais acometem os cães (Dantas-Torres et al. 2006; Jefferies et al. 2007). A doença é transmitida por carrapatos e resulta em diversas apresentações clínicas como: febre, palidez, icterícia, esplenomegalia, fraqueza, colapso associado com hemólise intra e extravascular, lesão hipóxica, inflamação sistêmica e trombocitopenia (Irwin 2005; Jacobson 2006).

O diagnóstico pode ser realizado pela visualização dos parasitas no interior dos eritrócitos ou livres no plasma, em esfregaços de sangue periférico corados pelo Giemsa e pela coloração de Romanowsky (Greene et al. 1993; Ungar de Sá et al. 2007). No entanto, essa técnica apresenta baixa sensibilidade, pois a parasitemia é variável, dificultando a visualização de eritrócitos circulantes parasitados, e pela dificuldade de se fazer a distinção morfológica precisa entre algumas espécies e subespécies. Por esses motivos, as técnicas moleculares, tais como a reação em cadeia da polimerase (PCR), tem sido aplicada, para detectar fragmentos de DNA de Babesia spp. e confirmar o diagnóstico da infecção (Birkenheuer et al. 2004). A PCR é uma técnica sensível e específica, para o diagnóstico da infecção para várias espécies do gênero Babesia, pois proporciona o diagnóstico em infecções agudas, subclínicas ou crônicas mesmo nos casos de baixa parasitemia (Macintire et al. 2002).
Estudos que relatam a prevalência de anticorpos anti-B. canis vogeli na região Nordeste são escassos. No estado do Maranhão, poucos estudos têm sido realizados sobre a babesiose canina, apesar de sua alta prevalência, e na cidade de São Luís, especificamente, nada foi publicado. Diante disso, este estudo teve como objetivo determinar a ocorrência de Babesia canis vogeli em cães na cidade de São Luís - MA.

\section{Material e Métodos}

O presente estudo foi realizado no município de São Luís, que possui área de $831,7 \mathrm{~km}^{2}$. O município faz parte da Mesorregião do Norte Maranhense e da Microrregião da Aglomeração Urbana de São Luís, localizadas a norte do Estado do Maranhão. A região está compreendida entre as coordenadas geográficas $\left(02^{\circ} 31^{\prime} 47^{\prime \prime} \mathrm{S} ; 4^{\circ}{ }^{\circ} 18^{\prime}\right.$ $10 \mathrm{~W}$ ), com uma população estimada de 1.082.935 habitantes (IBGE, 2014).

Foram avaliados 65 cães de ambos os sexos, de raças e idades variadas, com suspeita clínica de infecções por hemoparasitos, atendidos em clínicas particulares na cidade de São Luís - MA, Brasil. Após o exame clínico, amostras de sangue foram coletadas com EDTA para a pesquisa de Babesia pelos esfregaços sanguíneos diretos. Posteriormente, a mesma amostra foi utilizada para extração de DNA genômico, utilizando-se a tecnologia que envolve a lise celular, adesão para seletividade da membrana celular, remoção dos inibidores através de duas lavagens com PPS e eluição do DNA. A reação de PCR foi baseada na amplificação isotérmica para detecção qualitativa 
de Babesia vogeli em uma leitora específica para PCRun.

\section{Resultados e Discussão}

Dentre os 65 animais analisados por meio do diagnóstico direto, nenhum foi positivo para babesia spp. Após a realização do PCRun, observou-se que $5(7,69 \%)$ amostras foram positivas para $B$. canis vogeli, demonstrando a presença dessa espécie em cães provenientes de ambiente urbano na cidade de São Luís. O diagnóstico direto, embora simples e de fácil execução possui baixa sensibilidade (Harrus et al. 1997), pois fundamenta-se na visualização dos parasitas e avaliação do tamanho e morfologia das formas intra-eritrocíticas (Passos et al. 2005),

A taxonomia das espécies de Babesia de origem canina não se encontra totalmente definida, e por esse motivo o diagnóstico definitivo com base em critérios morfológicos pode ser questionado (Passos et al. 2005). Dessa forma, têm-se utilizado, cada vez mais, as técnicas de biologia molecular nos estudos que envolvem a etiologia e a epidemiologia da babesiose canina. Passos et al. (2005) realizaram o primeiro estudo em nível molecular com Babesiose canina e identificou cinco isolados como a subespécie $B$. canis vogeli, os quais apresentavam formas intraeritrocitárias $>2,5 \mu \mathrm{m}$.

No presente trabalho, o diagnóstico molecular permitiu a identificação conclusiva sobre o agente etiológico de cinco isolados, ao contrário do método de diagnóstico direto que foi inconclusivo, pois não detectou a infecção, e não é apropriado para a diferenciação entre as espécies de Babesia.

A biologia molecular tem contribuído muito para o diagnóstico dessa hemoparasitose, especialmente naqueles cães sintomáticos que não são positivos na pesquisa direta do agente no esfregaço sanguíneo. Além disso, os métodos moleculares permitem a delimitação entre as espécies e subespécies de Babesia spp., assim como relatado em diversos estudos epidemiológicos de diferentes países (Zahler et al. 1998; Cacciò et al. 2002; Matjila et al. 2005).

Estudos realizados no Brasil utilizando métodos moleculares encontraram valores semelhantes ao do presente trabalho, como O'Dwyer et al. (2009) que relataram a presença de infecção por Babesia spp. em 8\% dos cães de áreas rurais do estado de São Paulo. Ramos et al. (2010) observaram positividade de $7,31 \%$ de animais para B. canis vogeli em Pernambuco, Silva et al.
(2012) identificaram um percentual abaixo do encontrado no presente estudo, onde somente $3,33 \%$ dos animais analisados foram positivos para B. canis vogeli, na microrregião de Imperatriz, Maranhão.

Confrontando-se os resultados do diagnóstico direto com o diagnóstico molecular, observou-se que cinco animais foram falso-negativos no exame direto, além disso, esses resultados demonstram a baixa sensibilidade do diagnóstico direto, quando comparado ao PCR.

\section{Conclusão}

O diagnóstico da babesiose por esfregaço sanguíneo deve ser feita de maneira cautelosa, considerando-se a inespecificidade do teste. Os dados aqui apresentados indicam que a PCR é uma importante ferramenta de diagnóstico, superior ao diagnóstico direto, que pode ser utilizada para definir com maior precisão o estado de infecção dos cães por B. canis. Este estudo descreve, pela primeira vez, a confirmação de infecção por Babesia canis vogeli em cães na cidade de São Luís, Maranhão.

\section{Referências bibliográficas}

Birkenheuer A.J., Neel J., Ruslander D., Levy M.G. \& Breitschwerdt E.B. 2004. Detection and molecular characterization of a novel large Babesia species in a dog. Veterinary parasitology 124, 151-60.

Cacciò S.M., Antunovic B., Moretti A., Mangili V., Marinculic A., Baric R.R., Slemenda S.B. \& Pieniazek N.J. 2002. Molecular characterisation of Babesia canis canis and Babesia canis vogeli from naturally infected European dogs. Veterinary parasitology 106, 285-92.

Dantas-Torres F., Figueredo L.A. \& BrandãoFilho S.P. 2006. Rhipicephalus sanguineus (Acari: Ixodidae), the brown dog tick, parasitizing humans in Brazil. Revista da Sociedade Brasileira de Medicina Tropical 39, 64-7.

Greene C.E., Samperio J.O. \& Gómez J.P. 1993. Enfermedades infecciosas: Perros y gatos. Editora Interamericana, São Paulo.

Harrus S., Aroch I., Lavy E., Bark H., Redmond C., Hall G.A., Turnbull P.C.B., Gillgan J.S., Kobertz W.R. \& Wang D. 1997. Clinical manifestations of infectious canine cyclic thrombocytopenia. The Veterinary Record 141, 247-50. 
IBGE - Instituto Brasileiro de Geografia e Estatística. 2014. Produção da pecuária municipal. Rio de Janeiro, 42, 1-39.

Irwin P.J. 2005. Babesiose e cytauxzoonosis. In: Doenças infecciosas transmitidas por artrópodes do cão e do gato (eds. by S.E. S \& M.J. D), pp. 63-77. Manson Publishing, The Veterinary Press, Londres. UK.

Jacobson L.S. 2006. The South African form of severe and complicated canine babesiosis: clinical advances 1994-2004. Veterinary parasitology 138, 126-39.

Jefferies R., Ryan U.M. \& Irwin P.J. 2007. PCRRFLP for the detection and differentiation of the canine piroplasm species and its use with filter paper-based technologies. Veterinary parasitology 144, 20-7.

Macintire D.K., Boudreaux M.K., West G.D., Bourne C., Wright J.C. \& Conrad P.A. 2002. Babesia gibsoni infection among dogs in the southeastern United States. Journal of the American Veterinary Medical Association 220, 325-9.

Matjila T.P., Nijhof A.M., Taoufik A., Houwers D., Teske E., Penzhorn B.L., De Lange T. \& Jongejan F. 2005. Autochthonous canine babesiosis in The Netherlands. Veterinary parasitology 131, 23-9.

O'Dwyer L.H., Lopes V.V.A., Rubini A.S., Paduan K.D.S. \& Ribolla P.E.M. 2009. Babesia spp. infection in dogs from rural areas of São Paulo State, Brazil. Revista Brasileira de Parasitologia Veterinária 18, 23-6.

Passos L.M.F., Geiger S.M., Ribeiro M.F.B., Pfister K. \& Zahler-Rinder M. 2005. First molecular detection of Babesia vogeli in dogs from Brazil. Veterinary parasitology 127, 815.
Ramos R., Ramos C., Araújo F., Oliveira R., Souza I., Pimentel D., Galindo M., Santana M., Rosas E. \& Faustino M. 2010. Molecular survey and genetic characterization of tickborne pathogens in dogs in metropolitan Recife (north-eastern Brazil). Parasitology research 107, 1115-20.

Silva A.B., Costa A.P., De Sá J.C., Costa F.B., Santos A.C.G. \& Rita de Maria S.N.C. 2012. Detecção molecular de Babesia canis vogeli em cães e em Rhipicephalus sanguineus na mesorregião do oeste maranhense, nordeste brasileiro. Ciência Animal Brasileira 13, 38895.

Ungar de Sá M.F.M., Ungar de Sá J.E., Bittencourt D.V.V., Bispo A.C.D., Régis A.M.M., Souza Filho N.J., Gomes Neto C.M.B., Souza B.M.P.S., Bittencourt T.C.B.S. \& Franke C.R. 2007. Estudo retrospectivo (1991-2005), dos casos de babesiose canina na cidade de Salvador e Região Metropolitana, Bahia. Revista Brasileira de Saúde e Produção Animal 8, 178-83.

Zahler M., Schein E., Rinder H. \& Gothe R. 1998. Characteristic genotypes discriminate between Babesia canis isolates of differing vector specificity and pathogenicity to dogs. Parasitology research 84, 544-8.

Article History:

Received 16 January 2018

Accepted 1 March 2018

Available online 31 May 2018

License information: This is an open-access article distributed under the terms of the Creative Commons Attribution License 4.0, which permits unrestricted use, distribution, and reproduction in any medium, provided the original work is properly cited. 